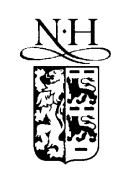

ELSEVIER
Journal of Economic Psychology 22 (2001) 745-772



www.elsevier.com/locate/joep

\title{
Fashions, habits and changing preferences: Simulation of psychological factors affecting market dynamics
}

\author{
Marco A. Janssen ${ }^{\mathrm{a}, *}$, Wander Jager ${ }^{\mathrm{b}}$ \\ a Department of Spatial Economics, Vrije Universiteit, De Boelelaan 1105, 1081 HV Amsterdam, \\ The Netherlands \\ ${ }^{\mathrm{b}}$ Faculty of Management and Organization, University of Groningen, Landleven 5, 9700 AV Groningen, \\ The Netherlands
}

Received 30 October 2000; received in revised form 18 June 2001; accepted 3 July 2001

\begin{abstract}
Markets can show different types of dynamics, from quiet markets dominated by one or few products, to markets with constant penetration of new and reintroduced products. This paper explores the dynamics of markets from a psychological perspective using a multi-agent simulation model. The behavioural rules of the artificial consumers, the consumats, are based on a conceptual meta-theory from psychology. The artificial consumers have to choose each period between similar products. Products remain in the market as long as they maintain a minimum level of market share, else they will be replaced by a new product. Assuming a population of consumats with different preferences, and social networks, the model simulates adoption of new products for alternative assumptions on behavioural rules. Furthermore, the consequences of changing preferences and the size of social networks are explored. Results show that the behavioural rules that dominate the artificial consumer's decision making determine the resulting market dynamics, such as fashions, lock-in and unstable renewal. Results also show the importance of psychological variables like social networks, preferences and the need for identity to explain the dynamics of markets. (c) 2001 Elsevier Science B.V. All rights reserved.
\end{abstract}

PsycINFO classification: $3000 ; 3920$

\footnotetext{
${ }^{*}$ Corresponding author. Tel.: +31-20-44-46092; fax: +31-20-44-46004.

E-mail addresses: m.janssen@econ.vu.nl (M.A. Janssen), w.jager@bdk.rug.nl (W. Jager).
} 
JEL classification: D11; E37; M31

Keywords: Social networks; Changing preferences; Consumer behaviour; Lock-in

\section{Introduction}

In daily life, consumers participate in many different markets. Some markets are stable and are dominated by one product, other markets are very unstable where new products are introduced frequently. Prices alone cannot explain the differences in market dynamics. Social processes appear to play an important role in market dynamics such as fads and fashions. For example, in toy industry, Tamagochi dominated for a brief period among young children, and this fad is disappeared in the same speed as it came. At the time of writing, Pokémon dominates many children's minds. It seems that besides price, also psychological factors have to be taken into consideration to explain diffusion of consumption patterns among social groups.

In this paper, we argue that different types of cognitive processing, changes of preferences, the focus of the need for identity and social networks are important determinants leading to product choice and explaining variations in market dynamics.

This paper is a follow up of Janssen and Jager (1999) which focussed on the dynamics of lock-in. Traditionally, lock-in dynamics or network effects are studied by increasing returns to scale (Arthur, 1994). The consumption of a particular product decreases the costs for other consumers, which increases the likelihood that other consumers also adopt the particular product. A small disturbance in an emerging market that favours one of the products can lead to a lock-in of the product. These increasing returns to scale explain dominance of certain products or technologies such as the traditional examples of the QWERTY keyboard, the VHS videotape standard and the dominance of Microsoft software (Arthur, 1994; David, 1985). Witt (1997) provides an alternative lock-in model in which newly introduced technologies can successfully disseminate in the market when a critical mass of adopters is derived. Such a critical mass might be derived by active marketing strategies. However, these lock-in studies do not explain 'local lock-ins', such as different clothing styles in different groups of society or the choice for a specific brand of cola. Since traditional models assume homogeneous populations, 
specific population structures such as social networks, might be possible explanations for local clustering of product choices. Dominance of products in social groups can often be explained from psychological factors stimulating social comparison and imitation. Various approaches have been used to explore such social processes in economic systems, starting with Veblen's (1899) introduction of 'conspicuous consumption', which holds that the intrinsic values of a product may be less important than the social meaning (see also Chao \& Schor, 1998). Relative income effect or 'Keeping up with the Joneses' has been introduced by Duesenberry (1949), who stated that an individual's utility from consumption depends not only on the absolute level of consumption, but also on how much is consumed in comparison to others. Several researchers have studied social processes in consumption, focussing at effects of relative consumption levels (Clark \& Oswald, 1994; Neumark \& Postlewaite, 1995), herding behaviour (Banerjee, 1992; Kirman, 1993), information cascades (Bikhchandani, Hirshleifer, \& Welch, 1992, 1998; Corneo \& Jeanne, 1999) and bandwagon effects (Granovetter \& Soong, 1986). An alternative approach is based on the notion that goods, which are bought frequently, are chosen non-cognitively which means that the choice is determined by reinforcement learning (Brenner, 1999). Our approach differs from these studies since the agents in our models do not always imitate or perform automatic behaviour, but switch between various cognitive strategies.

Compared with Janssen and Jager (1999), we introduce the possibility of launching new products and the possibility of preferences of consumers to change. We will present a multi-agent simulation model in which simulated consumers, the so-called 'consumats', choose every time-step which product to consume. The consumats decisions depend on how the products are expected to satisfy their needs. These needs are related to individual preferences as well as to the identity (social status) within a social network. We explore the consequences of different degrees of uncertainty tolerance and different minimum levels of satisfaction. As a sensitivity test, we explore the consequences of changing preferences and connectiveness of social networks.

The paper is built up as follows. In Section 2 we will discuss the changes of preferences from consumers. The structure of social networks is discussed in Section 3. Section 4 describes the conceptual framework to simulate artificial consumers, the consumats. The simulation model is described in Section 5 and the experiments with the model are reported in Section 6. Section 7 concludes. 


\section{Consumer behaviour and changing preferences}

Traditionally, economists consider preferences as fixed and given. The economist's task is to explore the consequences of a given set of preferences. Preference formation and change is considered to be a topic of psychological research. However, currently more and more economists discuss the relevance of preference change for economic research, and incorporate these ideas in their studies (Bowles, 1998; Güth \& Yaari, 1992; Pollak, 1978; Witt, 1991). These studies mainly focus on how markets and other economic institutions influence the evolution of preferences. Brenner (1999) points out that there are different types of learning processes that affect the preferences of consumers. However, there is no general model that distinguishes between social (exogenous) and individual (endogenous) preference change and the associated learning processes.

Psychological research states that the attributes that determine consumer preferences not only reside in the product, but also in the social setting in which the product is being used. Stated differently, the preference for a given product may partly depend on who else uses this product. The clothing-market with its fashions and high-status brands provides a clear example of a situation where preferences are strongly affected by 'role-models'. Here, we may observe that the consumption of others has two effects. First of all, people may experience a sense of belongingness when consuming the same product as their friends, peers and family. This can be attributed to the need for 'identity', which is related to a sense of belonging and having common symbols (Maslow, 1954; Max-Neef, 1992). However, in satisfying their need for identity, people may change their behaviour without changing their preferences.

The second effect of observing the consumption of others is described as the socialisation effect. Here people do change their preferences as a result of interpersonal contact. This socialisation effect holds that the personal preferences change in the direction of the characteristics of the product that is consumed the most by one's friends, peers and family. For example, people often learn to appreciate classical music if they perceive that acquaintances enjoy it very much (Becker, 1996; Bowles \& Gintis, 1976; Gintis, 1972). Of course learning from friends and increased listening experience significantly contribute to the appreciation of classical music. Nevertheless the socialisation effect may be the basic force that stimulates the initial liking of classical music. Elias (1984) extensively discusses this socialisation effect in describing the evolution of preferences in his work on the civilisation process. Hayakawa and Venieris (1977) empirically validated this argument with their 
finding that especially people with equal or higher status have an effect on one's consumptive behaviour. Generally, these effects can be interpreted as the outcomes of heuristics that employ the available social capital in a society (e.g., Hayakawa, 2000).

Besides via socialisation, consumer preferences may also change as a result of repeated consumption of a product. Zajonc (1968) demonstrated that the mere exposure to a stimulus, e.g., a nonsense word, people, abstract and representational visual images, and types of music, increases people's liking of these stimuli. This exposure effect has also been demonstrated in rats (Cross, Halcomb, \& Matter, 1967), suggesting that this is a deep-rooted principle in behavioural adaptation. Following a behaviouristic perspective, one would interpret this exposure effect as a strengthening of the stimulusresponse relation between product and preference (e.g., Foxall, 1990). Whereas people are born with certain preferences for food (e.g., sweet), many food preferences are being learned via cultural transmission (McCauley, Rozin, \& Schwartz, 1994). Stevenson and Yeomans (1995) experimentally demonstrated that people's preferences for the chilli-burn increased after consuming food that produced this sensation, without affecting the preferences for other foods. Zellner (1991) more generically states that the strong shift in preferences for foods that are initially disliked (e.g., coffee, chilli) can be explained by processes of mere exposure, social factors and conditioning. These processes may cause a stronger preference shift for products that are initially disliked than for products that are initially slightly disliked (e.g., many vegetables such as broccoli). These results suggest that the consumption of opportunities that are initially not satisfying may become more satisfying after repeated consumption. This type of process where people's preference for a product increases as a function of repeated consumption will be denoted as the exposure effect.

Based on these findings in literature, we distinguish two types of mechanisms how consumer preferences can change. The socialisation effect assumes that preferences change as a function of the proportion of people in the actor's social network that actually consumes this product. When sufficient agents in the social network of the consumers switch towards consuming another product, the preference of the consumer for that product is assumed to follow. The exposure effect assumes that when a product is repeatedly being consumed, the need satisfying capacity increases over time, independent of the actual satisfaction of consumption. It may be expected that these changes of preferences may narrow down the number of acceptable opportunities people have in their mind-sets, and hence introduce a resistance to behavioural change. 


\section{Structure of social networks}

Consumers interact with one another and thus learn about the consumptive behaviour of others by means of the social network they have. Two effects are typical for social networks, namely, the small-world effect and the clustering effect (Newman, 1999). The small-world effect refers to the experience that despite the large population, the map of who knows whom is such that we are all very closely connected to one another. The distance between two people in a society can be measured by the number "degrees of separation", where the links or degrees join the two through a series of intermediaries. It appears that the typical distance between any pair of people is remarkably small. This "small-world phenomenon" was confirmed by a study, conducted in the 1960s by Milgrams (1967). It indicated that most people are separated by on average only six degrees. Another interesting example is the analysis of the network of hyperlinks between documents on the World Wide Web. Despite about a billion of documents on the web, the average distance between documents was estimated only to be about 19 hyperlinks (Albert, Jeong, \& Barabási, 1999). Social networks seem to be structured in such a way that information can be spread fast over the social network. Another aspect of social networks is the existence of clusters.

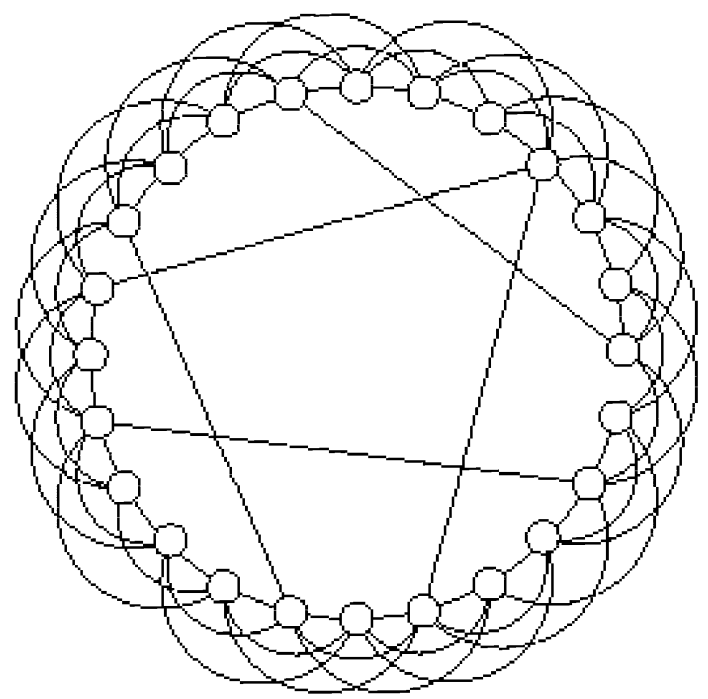

Fig. 1. A Watts-Strogatz model of social networks. 
People's circles of acquaintance tend to overlap to a great extent. Your friend's friends are likely also to be your friends.

Watts and Strogatz (1998) proposed a model for social networks, which fits very well on both small-world and clustering characteristics, and is therefore used in this paper to represent social networks. Their suggestion was to build a model that is a regular lattice that has some degree of randomness in it (Fig. 1). They construct the network by taking a lattice of periodic boundary conditions, and go through each of the links on the lattice and with some probability $s$ that link is rewired by moving one of its ends to a new randomly chosen position. It can intuitively be seen that the network has both clustering and small-world effects. More formal discussions on the characteristics of these types of networks can be found in Watts and Strogatz (1998) and Newman (1999).

\section{The consumat approach}

Many behavioural theories, like theories about human needs, motivational processes, social comparison theory, social learning theory, theory of reasoned action and so on, all explain parts of the processes that determine consumer behaviour. Social psychology is often discussed to be in a preparadigm state. According to some scholars there is a need for a meta-theory of human behaviour (Vallacher \& Nowak, 1994). The consumat approach is based on a comprehensive conceptual model of consumer behaviour (Fig. 2), and as such tries to offer such a meta-theory (e.g. Jager, 2000).

Based on this conceptual model, a multi-agent simulation approach has been developed. The driving forces at the collective (macro) and the individual (micro) level determine the environmental setting for the consumat behaviour. The collective level refers to technical, economical, demographic, institutional and cultural developments, and thus describes the world the consumats are living in. The individual level refers to the consumats, who are equipped with needs which may be more or less satisfied, and are confronted with opportunities to consume, and that have various abilities to consume the opportunities. Furthermore, consumats have a certain degree of uncertainty, depending on the difference between expected and actual outcomes of their behaviour.

The consumats may engage in different cognitive processes in deciding how to behave, depending on their level of need satisfaction and their experienced degree of uncertainty. Consumats having a low level of need satisfaction and a low degree of uncertainty are assumed to deliberate, that is: to determine 


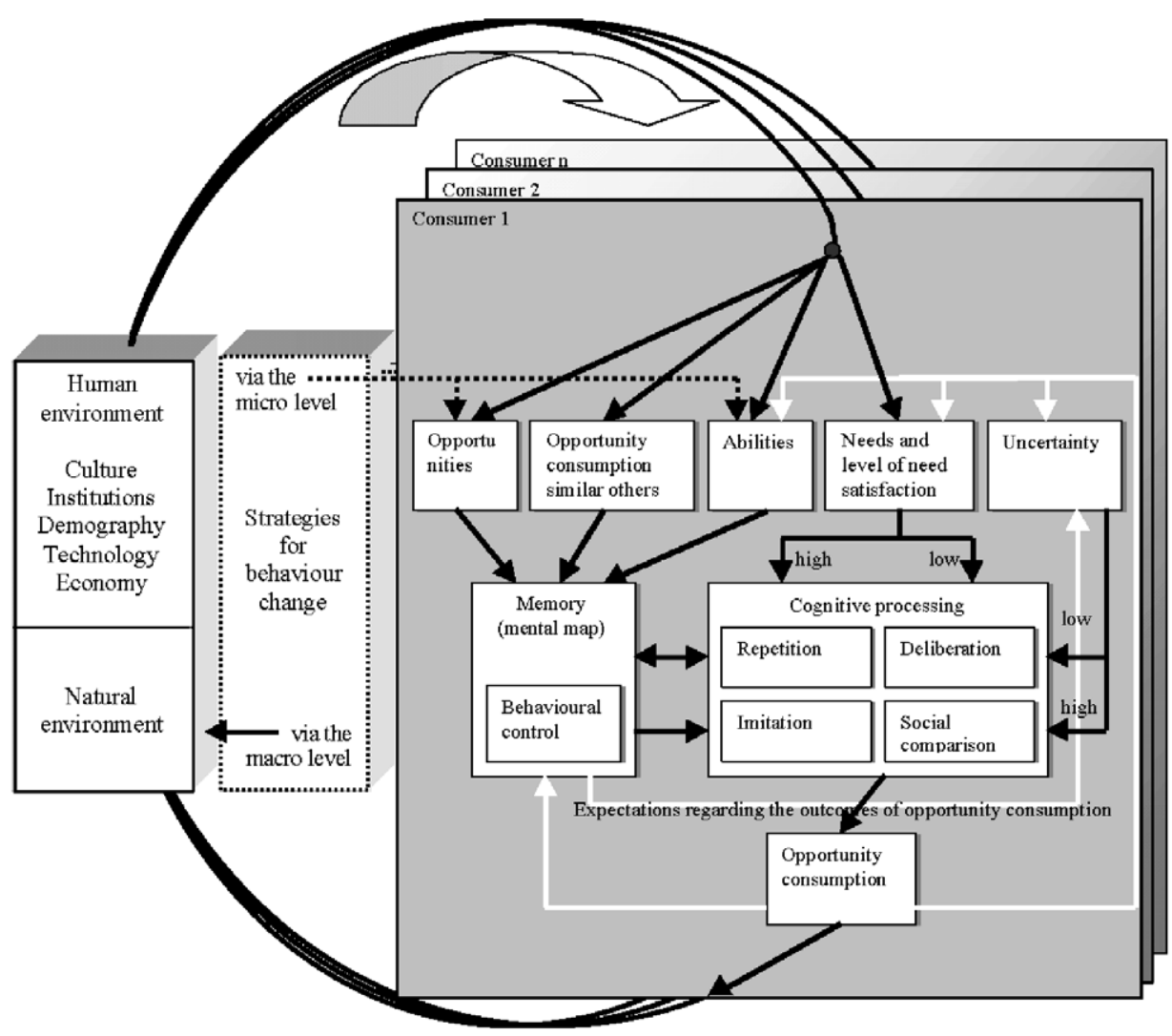

Fig. 2. The conceptual model of consumer behaviour.

the consequences of all possible decisions given a fixed time-horizon in order to maximise their level of need satisfaction. This type of decision making is described as optimising (Janis \& Mann, 1977), and described in the Theory of Reasoned Action (Fishbein \& Ajzen, 1975) and the Theory of Planned Behaviour (Ajzen, 1991). People may use various decision rules while deliberating, such as conjunctive decision rules, elimination by aspects and lexicographical decision rules. In the formalisation of the consumat approach we confined ourselves to a simple maximisation rule, which allows for compensating the scores on different need satisfiers. Consumats having a low level of need satisfaction and a high degree of uncertainty are assumed to socially compare. This implies the comparison of own previous behaviour with the previous behaviour of consumats having about similar abilities, and 
selecting that behaviour which yields a maximal level of need satisfaction. This type of decision making is described by Social Comparison Theory (Festinger, 1954) and includes group comparisons (Faucheux \& Moscovici, 1972). When consumats have a high level of need satisfaction, but also a high level of uncertainty, they will imitate the behaviour of other similar consumats. Imitation focuses on (the outcomes of) the behaviour of other people, and, because it does not involve extensive elaboration on the consequences of performing that behaviour oneself, it requires less cognitive effort than social comparison. Yet, imitation requires more cognitive effort than repetition (habitual behaviour), because one should be attentive to the behaviour of someone else and understand and remember that behaviour (Bandura, 1986). This type of decision making is described by Social Learning Theory (Bandura, 1986), Social Impact Theory (Latané, 1981) and the Theory of Normative Conduct (Cialdini, Kallgren, \& Reno, 1991). Finally, consumats having a high level of need satisfaction and a low level of uncertainty habitually repeat their previous behaviour. The principles behind this type of decision making have been described by Classical Conditioning Theory (Pavlov, 1927) and Operant Conditioning Theory (Skinner, 1953). When consumats engage in reasoned behaviour (deliberation and social comparison) they will update the information in their mental map, which serves as a memory to store information on abilities, opportunities, and characteristics of other agents. When a mental map is not being updated, the information may become obsolete, and the consumat can be said to have a mind-set that excludes new, possible more attractive opportunities for consumption.

Markets differ with respect to the type of cognitive processing that dominates consumers' decision making. When certain products are frequently being bought (e.g., groceries in a supermarket), and consumers are satisfied with the products, it would be a waste for consumers to spend too much time (cognitive effort) on the decision making process. Because people have limited cognitive resources (e.g., Newell \& Simon, 1972; Shiffrin, 1975), it would be more efficient to allocate their cognitive resources to important nonroutine decisions. Hence, in supermarkets and the like consumers decide usually in a more automatic (habitual) way (repetition or imitation). This allows one to spend considerable time contemplating about a problem on the job, planning next weekend or daydreaming whilst doing the daily shopping. However, when consumers are confronted with a decision with large consequences for their satisfaction (e.g., a new car or a hi-fi set), they will be motivated to invest more time (cognitive effort) in making a decision (deliberation or social comparison). The level of uncertainty consumers 
experience in finding a satisfactory product largely determines the degree to which they use social information in their decision making process (imitation, social comparison). Especially when products have an important social connotation (e.g., cars, clothing) it is more likely that social decision making will dominate the market.

After the consumption of opportunities, a new level of need satisfaction will be derived, and changes will occur regarding their abilities, opportunities and the social and physical environment, which will affect the consumption in succeeding time-steps. In the following section, we will formalise the consumat approach for a dynamic market with a fixed number of products.

\section{The model}

A simple dynamic market system is developed in which 100 consumats consume one product on every time-step. Products are assumed to differ from each other on two dimensions, $d_{1}$ and $d_{2}$, which are defined for a range from 0 to 1 . For simplicities sake a fixed amount of 10 products are assumed to be available on the market. The products have randomised characteristics on these dimensions. When a product is introduced on the market it gets an introduction period $t_{i}$ to built up a market share. After this introduction period the product should have a minimum market share of $m_{\min }$ in order to remain on the market, else it is being replaced by a new product.

The survival of products on the market depends on whether consumats consume the products. The model below describes the behaviour of one consumat. The choice which product to consume depends on the expected need satisfaction by consumption of the particular product. We assume that prices of the products are similar and are not the discriminating factor between products for the consumer in order to make a choice. The level of need satisfaction depends on an individual need and a social need. The individual need is assumed to be the personal taste of the consumat. Each consumat has a specific personal taste for each of the two dimensions of the product. The level of need satisfaction for personal taste of consumat $i, N_{\mathrm{p}, i}$ depends on the difference between the dimensions of the consumed product and the preferred characteristics by the consumat, $p_{1, i}$ and $p_{2, i}$ :

$$
N_{\mathrm{p}, i}=1-\frac{\sqrt{\left(p_{1, i}-d_{1}\right)^{2}+\left(p_{2, i}-d_{2}\right)^{2}}}{\sqrt{2}} .
$$


The level of need satisfaction for the social need $N_{\mathrm{s}, i}$ depends on how many other consumats in the social network of the consumat consume the same product. The social network is implemented in line with the Watts-Strogatz model (Fig. 1). A social network of a particular consumat consists of the neighbours of the consumat, that is the directly linked agents in the WattsStrogatz model. The level of need satisfaction of the social need, $N_{\mathrm{s}, i}$, is equal to $m s_{i}$, the market share in the social network of the product that is consumed by the consumat itself. This holds when we assume that $N_{\mathrm{s}, i}$ is higher the more consumats in the social network consume the same product. We acknowledge that there are various ways to implement the identity need. Especially the stable relations we formalise between a fixed set of agents within the social network seem to contrast with the changing relations and network sizes one may witness in the real world. However, in order to demonstrate the basic effects of social networks, assuming that real world networks are often quite stable over a yearly period, we decided to use the approach as described above.

$$
N_{\mathrm{s}, i}=m s_{i} .
$$

The total level of need satisfaction is equal to

$$
N_{i}=\beta_{i} \cdot N_{\mathrm{s}, i}+\left(1-\beta_{i}\right) \cdot N_{\mathrm{p}, i},
$$

where $\beta_{i} \in[0,1]$ weights the influence of the social need and the personal taste need. When $\beta_{i}$ equals 0.5 , both needs weight equally in the total level of need satisfaction.

The stability of the environment people live in may vary considerably. When the environment is unstable, people may experience different consequences of their behaviour than expected. Here, we define uncertainty, $U_{i}$, as the difference between expected $N_{i}$, which is assumed to be equal to $N_{i}$ at time $t-1$, and the actual $N_{i}$ :

$$
U_{i}=\left(N_{i}-N_{i, t-1}\right)^{2} \text {. }
$$

The threshold parameters $N_{\min }$, the minimum level for satisfaction, and $U_{\max }$, the uncertainty tolerance level, are given. Given the values of $N_{i}$ and $U_{i}$ the type of cognitive processing of the consumat can be defined. A complicating factor is the fact that products disappear from the market. In such cases, the consumats can not habitually repeat consumption, and in case of social processing, these products can not be considered as candidates for adoption.

- Repetition (satisfied and certain: $N_{i}>N_{\min } ; U_{i}<U_{\max }$ ). The consumat habitually consumes the product it consumed last time-step. 
- Deliberation (dissatisfied and certain: $N_{i}<N_{\min } ; U_{i}<U_{\max }$ ). The consumat will evaluate the expected $N_{i}$ of each product, and consumes the product with the highest score. When two or more products have the highest score, the choice is at random between the candidate products.

- Imitation (satisfied and uncertain: $N_{i}>N_{\min } ; U_{i}>U_{\max }$ ). The consumat evaluates the product which is consumes the most in its social network. The product, which is consumed the most in the previous time-step, will be chosen for current consumption. In case of more than one candidate, the choice is at random between the candidate products.

- Social comparison (dissatisfied and uncertain: $N_{i}<N_{\min } ; U_{i}>U_{\max }$ ). The consumat evaluates the product that is consumed the most in its social network. A candidate product is a product that will at least reach an expected $N_{i}$ as the consumats' $N_{i}$ in the last time-step. The candidate product with the highest market share will be chosen for consumption, and in case of more than one of these products, the choice will be at random.

\subsection{Preference change}

As described in Section 2 two mechanisms can be distinguished to determine preference change. These are formalised as follows:

1. Socialisation. The value $p_{1, i}$ and $p_{2, i}$ are equal to $d_{1}$ and $d_{2}$ of the product that has the largest market share in the social network. If there is a tie for the largest market share, the choice is made at random.

2. Exposure. The value of the preference $p_{j, i}$ depends on the difference between the consumed product characteristic $d_{\mathrm{c}, i}$ and the preference, and the preference is adjusted at rate $\gamma_{c}$. Setting $\gamma_{c}$ allows for defining the strength of the exposure effect:

$$
\partial p_{j, i} / \partial t=\left(d_{\mathrm{c}, i}-p_{j, i}\right) \cdot \gamma_{\mathrm{c}} .
$$

\section{Experiments}

Consider a market of 100 consumats and 10 products. The minimum market share for a product to survive is set at $10 \%$, and the introduction period is equal to five time-steps. Preferences remain constant over the timeperiod. Each time-step consists of a period of about a day up to a week. Brief enough to assume a constant social network. A Watts-Strogatz social net- 
work is defined where agents are connected with their four nearest neighbours and randomly to each possible other agents, using a probability of $1 \%$. The value of $\beta_{i}$, which weights the two needs, is drawn randomly for each consumat from a uniform distribution between 0 and 1 . The preferences of the consumats for dimensions 1 and 2 are also drawn from a uniform distribution between 0 and 1 . The same holds for the characteristics of the 10 products.

\subsection{Single run default experiments}

We will first present a number of single run experiments to demonstrate the typical market dynamics for different conditions. These conditions are based on different values of $N_{\min }$ and $U_{\max }$, and named after the cognitive process that is being favoured by these settings. Five conditions are being used: (1) imitators: $N_{\min }=0.1$ and $U_{\max }=0.1$; (2) repeaters: $N_{\min }=0.1$ and $U_{\max }=0.9$; (3) comparers: $N_{\min }=0.9$ and $U_{\max }=0.1$; (4) deliberaters: $N_{\min }=0.9$ and $U_{\max }=0.9$; (5) random: $N_{\min }$ and $U_{\max }$ are drawn random between 0 and 1, using a uniform distribution. For each condition, we will depict the average distribution of cognitive processes and the market shares of the 10 products for a typical model run.

\subsubsection{Imitators}

Fig. 3 summarises the results for a typical imitators run. Local lock-ins can be observed, where a few products ends up dominating a local part of market (Fig. 3(b)). Because the consumats are easily satisfied $\left(N_{\min }=0.1\right)$, but also very quickly uncertain $\left(U_{\max }=0.1\right)$, they are mainly engaging in imitation during the first time-steps (Fig. 3(a)). This imitation causes that after about 10 time-steps the consumats consume in clusters the same product, thereby pushing the alternative products out of the market. Because they consume in clusters the same product, uncertainty drops due to an increased $m s_{i}$, making the consumats certain. Moreover, the chosen products become more attractive because of their higher need satisfying capacity for identity, and as a result the overall level of need satisfaction increases. Being certain and satisfied, the consumats exclusively engage in repetition after time-step 20, thereby creating a stable market. Because a lot of consumats consume the same product, thereby satisfying their need for identity, their overall $N_{i}$ is moderately high, despite the fact that products may exist that would further increase their level of need satisfaction for taste. 



Fig. 3. (a) Fraction of cognitive processing for the imitator condition. (b) Market share of products for the imitator condition.

Examples of such locked-in markets refer typically to dominance of products in local domains of social networks, such as clothing styles, choice for certain brands of cola and choices for modes of transportation.

\subsubsection{Repeaters}

In Fig. 4, the results for a typical model run with repeaters are being shown. Here we see a market in which four products have relative stable 

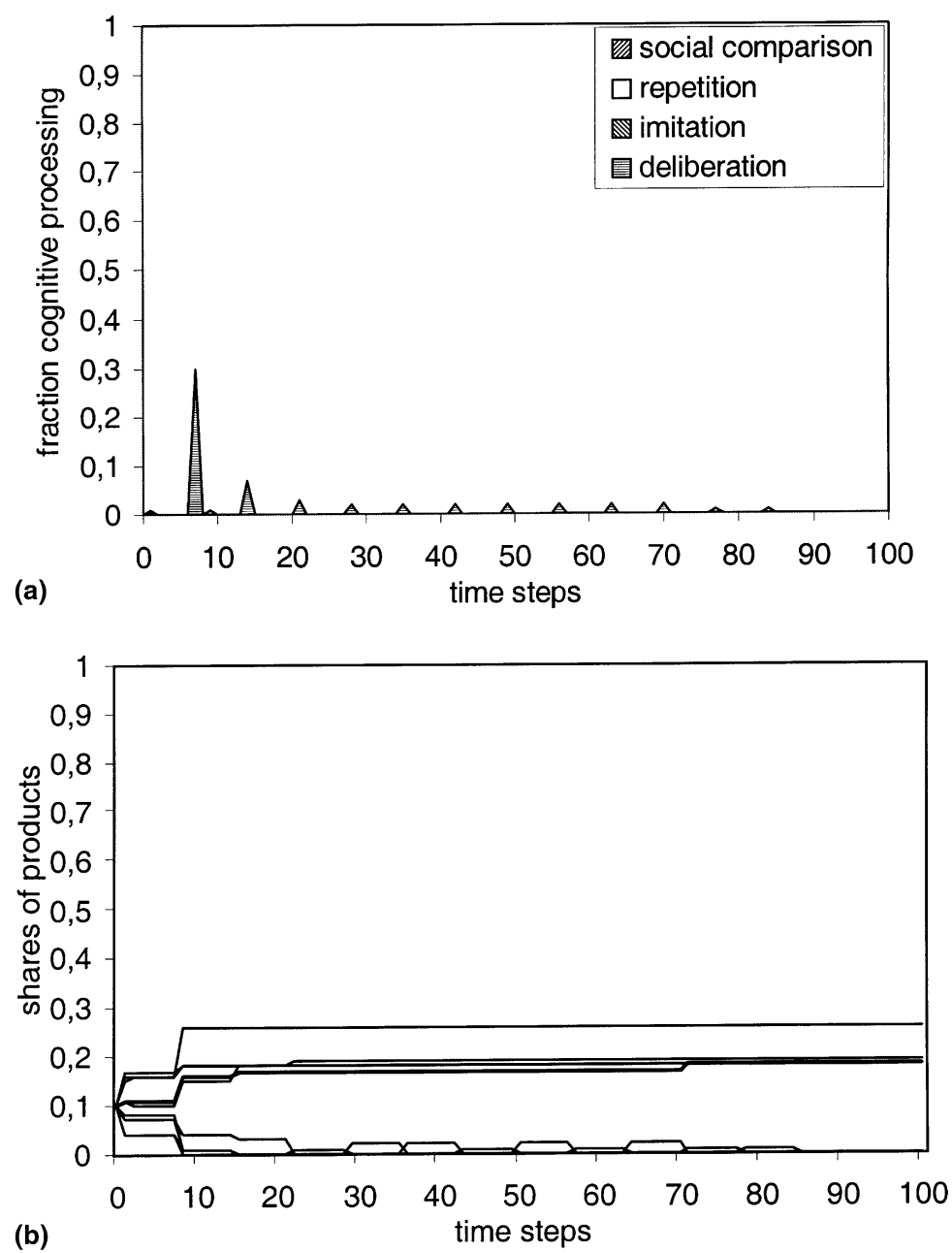

Fig. 4. (a) Fraction of cognitive processing for repeater condition. (b) Market share of products for the repeater condition.

market-shares, and at the 'bottom' of the market several products are introduced and disappear after a while (Fig. 4(b)). Because the consumats have a high uncertainty tolerance $\left(U_{\max }=0.9\right)$, they do not engage in social processing. Most consumers engage in repetition, and hence the market share of a number of opportunities is very stable, as can be seen in Fig. 4(b). A number of consumats sometimes engages in deliberation. Those consumats initially consumed a product that disappeared from the market because of the 
low market share. Those consumats engage deliberation and choose the best one. However, they might have chosen one of the new entries which are not likely to remain after the introductory process. Therefore deliberation occurs on a regular frequency (related to introductory period) for a decreasing number of consumats.

Because many consumers consume different products, the consumats' network will not display uniform product consumption. As a consequence the level of need satisfaction for identity will remain at a relative low level.

Such a market resembles the daily shopping of most people, and refers to products such as coffee, toothpaste and milk. Here, people may use different brands and buy them in a habitual manner, not deliberating about it. Moreover, people are quite certain of the outcomes of consumption. Consequentially, the market is not being dominated by uncertainty and related social processes. When a consumer is not satisfied with a product, he/she may engage in deliberation and decide to use another product, which is then being used in a habitual manner.

\subsubsection{Comparers}

Fig. 5 displays the results for a typical model run with comparers. Here, the consumats are very hard to satisfy $\left(N_{\min }=0.9\right)$, and very quickly uncertain $\left(U_{\max }=0.1\right)$. As a consequence, the consumats engage primarily in social comparison and deliberation, as can be seen in Fig. 5(a). Regarding the market dynamics we observe large oscillations (Fig. 5(b)). What can be clearly seen is that one product has the largest share for almost the entire simulation period. Only around $t=30-35$ the product denoted with the dotted line has the largest market-share. In this condition, the social comparison process causes that many consumats are starting to consume the same product. This equal consumption leads to a lower uncertainty, stimulating the consumats to engage in deliberation. As a consequence, a number of consumats perceive new attractive products, which, when attractive enough, may conquer a relative large market-share due to comparison processes. However, after some time the 'old' dominating product may push the other product out of the market because it better satisfies individual needs.

This type of market typically resembles fashion markets for repetitively bought products (clothing, hair-cuts, Pokémon cards, home decoration), where people are at given moments uncertain regarding what is in vogue, and think it is very important that they consume in a fashionable manner. Especially young adolescents, who are often very uncertain regarding their 

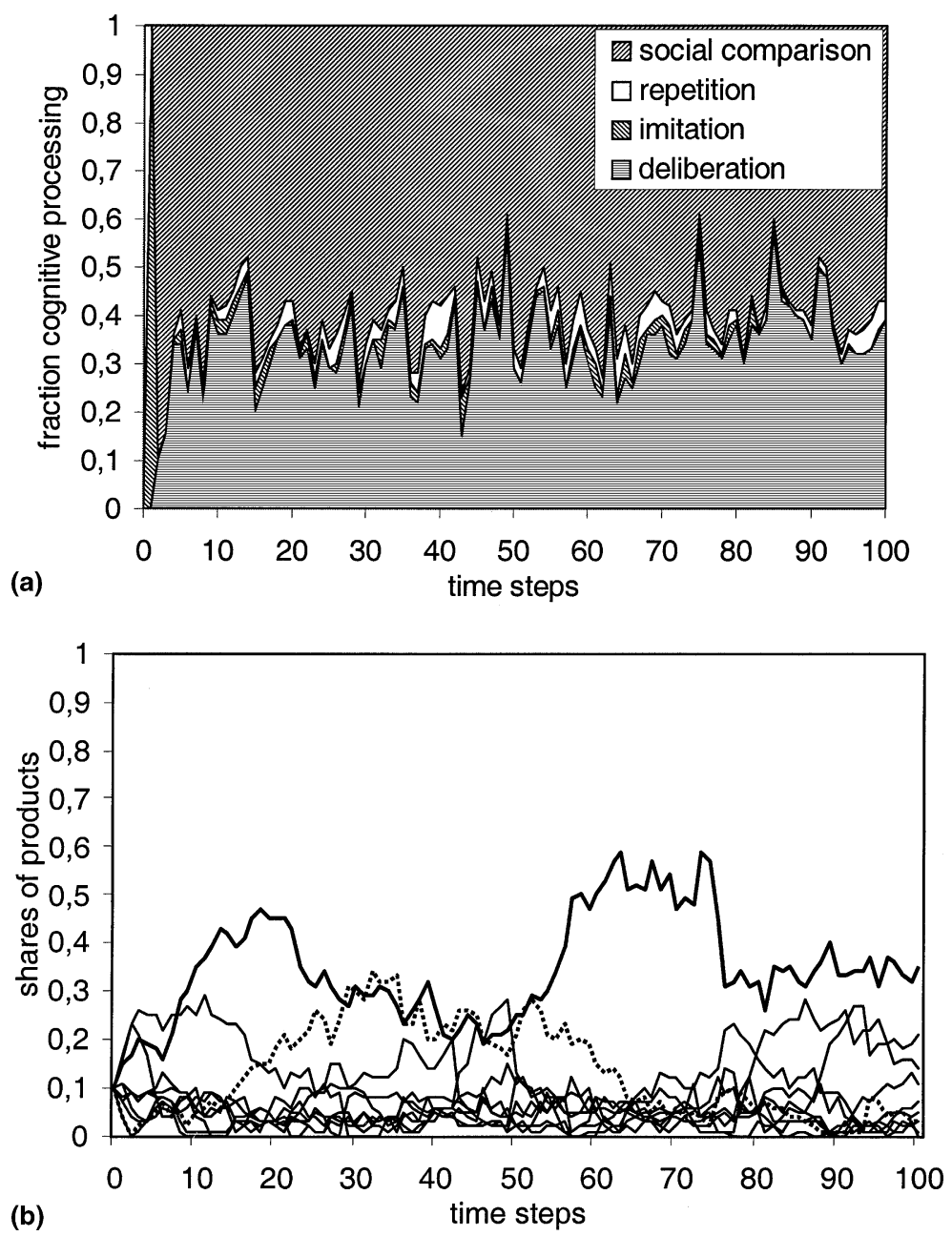

Fig. 5. (a) Fraction of cognitive processing for the comparer condition. (b) Market share of products for the comparer condition.

developing identity, such fashion effects may be very important in their consumptive behaviour.

\subsubsection{Deliberaters}

Fig. 6 show the results of a typical model run with deliberators. Here we see an unstable market, where products may remain at the market for a prolonged period of time, but without having a fixed market share (Fig. 6(b)). 



Fig. 6. (a) Fraction of cognitive processing for the deliberator condition. (b) Market share of products for the deliberator condition.

Because the consumats here are very hard to satisfy $\left(N_{\min }=0.9\right)$, and very certain $\left(U_{\max }=0.9\right)$, they are engaging almost exclusively in deliberation, as can be seen in Fig. 6(a). This causes that new products may immediately attract a number of consumats for which this product better satisfies their preferences. Because the consumats that consume the new product previously may have consumed different products, the market shares of several other products may drop somewhat. 
This simulation run appears to capture the dynamics of markets of durable goods (e.g., washing machines and refrigerators), and financial services (e.g., insurance and loans). Here, people are motivated to get the best value for their money, whereas they are quite certain about the outcomes. Hence, they are not likely to engage in social processing, but rather deliberate about what would be their optimal consumption pattern. This results in a continuously evolving market, where market-shares are unstable.

\subsubsection{Random}

Fig. 7 shows the results for a typical run with random consumats. It can be seen that that when the thresholds determining the cognitive processing $\left(N_{\min }\right.$ and $\left.U_{\max }\right)$ vary over the population of consumats, all four type off cognitive processes are used among the population of consumats, although repetition and deliberation dominate. The results show that the market dynamics are a combination of Fig. 4 (mainly repetition) and Fig. 6 (mainly deliberation).

\subsection{0 runs default experiments}

In the previous section we showed some typical runs, demonstrating how different settings of $N_{\min }$ and $U_{\max }$ yielded different market dynamics, varying from lock-ins of a few products, fashion markets to unstable markets with a lot of renewal. In this section, we will report the results of 100 runs for the five conditions described in the earlier section in order to obtain a more thorough picture of the effects. A simple indicator of the type of market that emerges is the number of products that succeed in surviving some time after the introduction period. In case of a lock-in of one product, this amount of products will be equal to one, but in case of unstable markets this can go up to 40 products in a simulation period of 100 time-steps, as products may be replaced after some time.

Fig. 8 depicts the results for the 100 runs for each of the five conditions. The results are in line with the typical model runs as discussed in the previous section. For the imitator condition, we observe that only about three or four products survive the introduction period, while in the repeaters condition this amount of is equal to five or six. These low numbers can be explained by local lock-ins of the products. The conditions with comparers and deliberaters show much higher numbers of products. Especially in the condition with deliberaters are the individual tastes important, leading to small and shortlived market shares. 

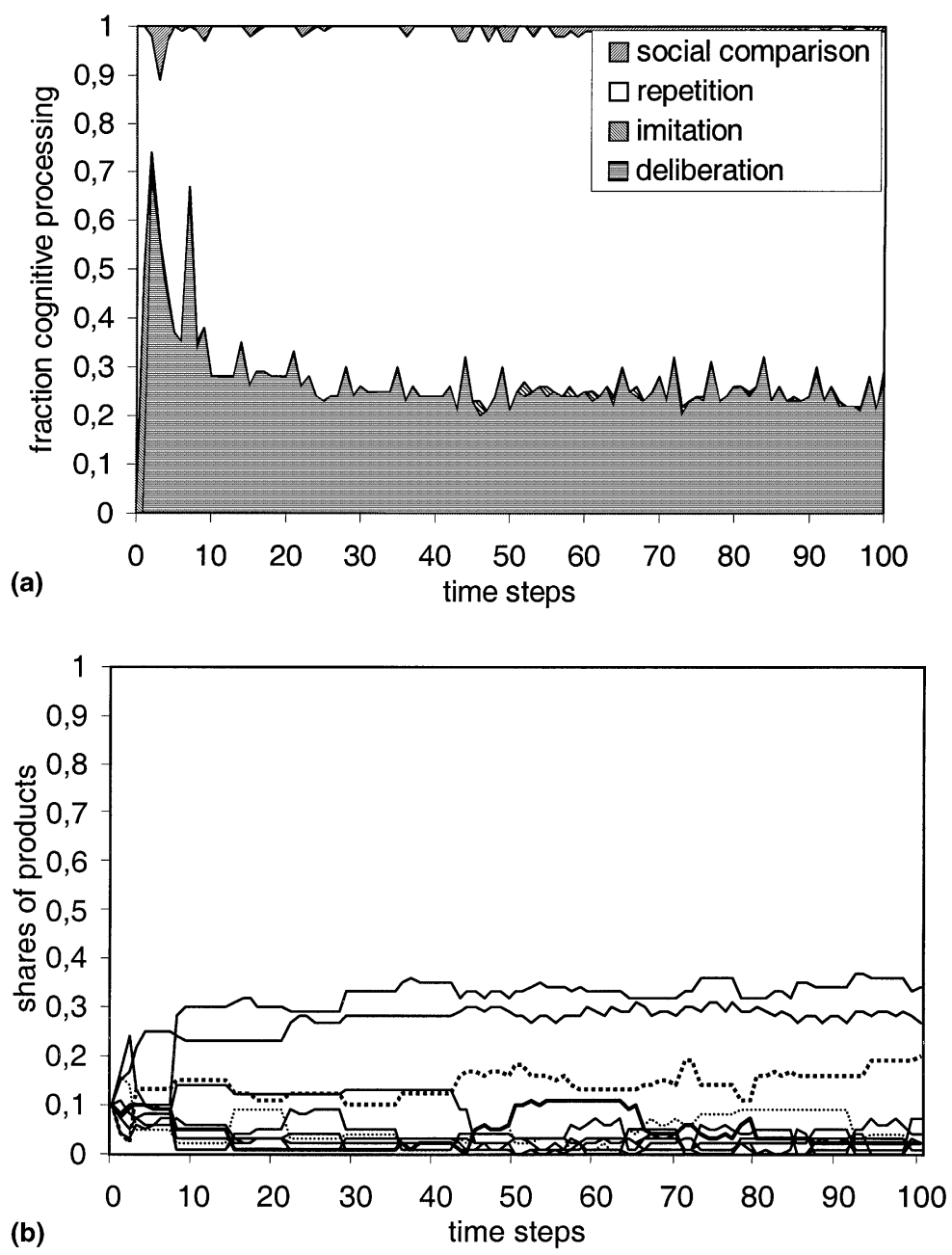

Fig. 7. (a) Fraction of cognitive processing for the random condition. (b) Market share of products for the random condition.

\subsubsection{Experimenting with changing preferences}

A number of experiments have been performed to explore the consequences of changing preferences using both types of possible preference change, namely, via the process of socialisation and the process of exposure. In Table 1, we give an overview of the number of products that succeed in surviving some time after the introduction period for the default runs as discussed in the earlier section, and the two preference change types. 

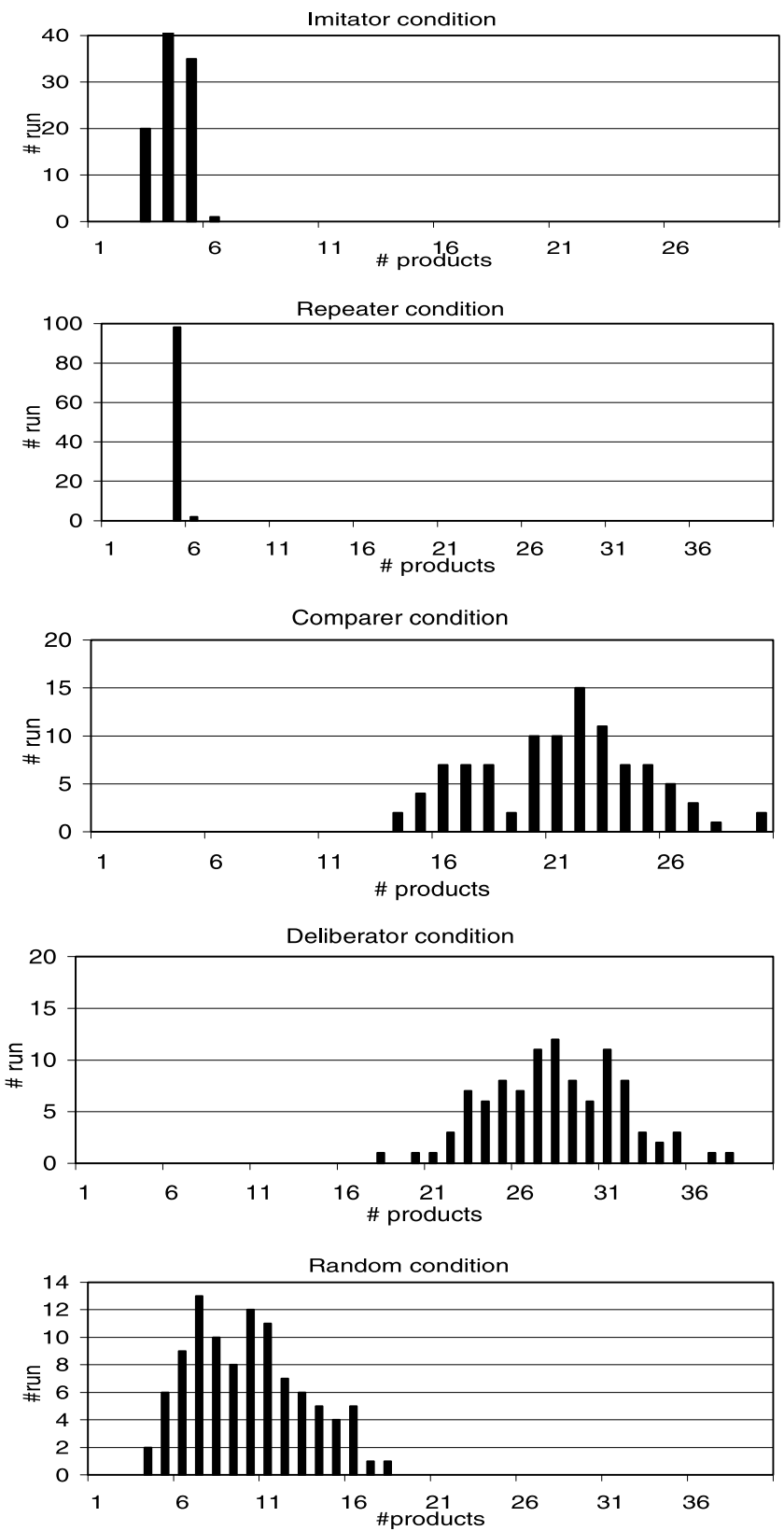

Fig. 8. Distributions of number of products that survived (some time) following the introduction period during 100 time-steps, for 100 runs per condition. 
Table 1

The average number of products which penetrate the market in a period of 100 time-steps

\begin{tabular}{llllll}
\hline & Imitators & Repeaters & Comparers & Deliberators & Random \\
\hline Default & 4.3 & 5.0 & 16.7 & 30.3 & 7.9 \\
Socialisation & 3.8 & 5.0 & 3.8 & 5.8 & 4.1 \\
Exposure & 3.9 & 5.1 & 15.4 & 29.8 & 8.1 \\
\hline
\end{tabular}

Three cases are distinguished, the default case, the socialisation type of preference change and the exposure type of preference change. Furthermore, five types of consumats are distinguished.

In case of imitators, both types of preference change increase the chance of a product to lock in. Preference change leads to higher satisfaction of consuming the products of neighbours in the social network (socialisation), or for consuming the same product as in the previous time-step (exposure). Because in the condition with repeaters the consumats will mainly engage in repetition, these results will not change. In the condition with comparers, there is a high chance of lock-in when preferences change through socialisation, whereas in case of exposure the market remains unstable. Social comparison and socialisation stimulates each other into a lock-in. For the deliberaters, we find that introducing socialisation yields a bifurcation in the results. The number of penetrated products is concentrated around five, and around 15. When a critical number of consumats is satisfied, they will engage in repetition, and thereby form a critical mass that will affect the preferences of other consumats via socialisation, and hence stimulate the lock-in of products. When this critical mass is not reached, the consumats remain switching between products, thereby not reaching a stable market. In this condition, the exposure type of preference change hardly affects the market dynamics.

The clustering of consumption also draws a picture of market dynamics. An indicator of this clustering is the fraction of closest two neighbours consuming different products. When this fraction is equal to 1 , then the neighbours left and right in the circle consume a different product. When this fraction is equal to zero, every consumat consumes the same product. In Table 2, the fractions are depicted for all five conditions. These results show the large degree of clustering in case of imitators. Also in the conditions of comparers, deliberators and random we observe a strong clustering of consumption when preferences change according to the socialisation mechanism.

\subsubsection{Experimenting with the size of the network}

Another factor that is supposed to affect market dynamics is the size of the network. The social network consists of links between consumats. The 
Table 2

Average fraction of consumers neighbours who consume a different product (for $t=100$ )

\begin{tabular}{llllll}
\hline & Imitators & Repeaters & Comparers & Deliberators & Random \\
\hline Default & 0.34 & 0.92 & 0.74 & 0.94 & 0.88 \\
Socialisation & 0.27 & 0.86 & 0.27 & 0.26 & 0.29 \\
Exposure & 0.30 & 0.92 & 0.73 & 0.94 & 0.88 \\
\hline
\end{tabular}

Three cases are distinguished, the default case, the socialisation type of preference change and the exposure type of preference change. Furthermore, five types of consumats are distinguished.

more links, the larger the social network and the faster information can be processed. In the previous experiments, the consumats had contact with their four nearest neighbours and had a $1 \%$ chance, $s$, of having contact with any of the other consumats. With this setting the consumats had on the average five others in their social network. In this experiment, we vary the chance of contact with any other consumat. Setting $s$ at $0 \%$ implies that the consumat has only contact with its closest four neighbours. Setting $s$ at $10 \%$ implies that the consumat has contact with on the average about 10 other consumats, additional to the four closest neighbours. In the latter condition, the consumat has contact with about 14 other consumats.

In most of the five conditions we observe that the more links in the social network, the lower the amount of products that have survived (Table 3), indicating a lock-in. Especially when the consumats engage a lot in social processing (imitators and comparers), larger networks leads to faster dominance of one or a few products.

The indicator values of Table 4 show that the level of small-world effect has only significant impact in case consumats mainly imitate. In the case of more connections, all consumats become to consume the same due to a global lock-in.

Table 3

The average number of products which penetrate the market in a period of 100 time-steps

\begin{tabular}{lllllr}
\hline & Imitators & Repeaters & Comparers & Deliberators & Random \\
\hline$s=0 \%$ & 4.1 & 5.0 & 17.9 & 30.1 & 7.2 \\
$s=1 \%$ (default) & 4.3 & 5.0 & 16.7 & 30.3 & 7.9 \\
$s=10 \%$ & 1.1 & 5.0 & 8.2 & 29.9 & 10.9 \\
\hline
\end{tabular}

Three types of social networks are distinguished, the default case, the network with no cross-cutting links, $s=0 \%$, and a network with more cross-cutting links. Furthermore, five types of consumats are distinguished. 
Table 4

Average fraction of consumers neighbours who consume a different product (for $t=100$ )

\begin{tabular}{llllll}
\hline & Imitators & Repeaters & Comparers & Deliberators & Random \\
\hline$s=0 \%$ & 0.33 & 0.92 & 0.73 & 0.94 & 0.87 \\
$s=1 \%$ (default) & 0.34 & 0.92 & 0.74 & 0.94 & 0.88 \\
$s=10 \%$ & 0.00 & 0.92 & 0.71 & 0.94 & 0.90 \\
\hline
\end{tabular}

Three types of social networks are distinguished, the default case, the network with no cross-cutting links, $s=0 \%$, and a network with more cross-cutting links. Furthermore, five types of consumats are distinguished.

\section{Conclusions}

This paper demonstrates that market dynamics can be highly susceptible to the cognitive processes that dominate the consumers' decision making process. Products that are relevant for peoples' identity need, and that quickly satisfy consumers' needs, are most likely to lock in. Especially when people imitate the probability of a lock in is high. Products that fit these dynamics are, e.g., coffee, toothpaste and milk for the repeater condition, and public visible products such as clothing styles, brands of cola and mode of transportation for the imitator condition. It is often very hard to enter such a fixed a market with a new product. A strategy that may be viable is to attach a new need satisfying capacity to the product image, thereby adding a motive to buy this product. The suggestion that drinking a certain brand of cola (e.g., Pepsi Max) adds to your experienced freedom in life is a typical example of such a 'motive adding strategy', just as claiming that a certain brand of toothpaste adds to your sense of confidence.

It appears that a preference chance of consumers hardly affects these market dynamics. The size of the network has a serious effect in the imitator condition. This effect suggests that in a market that is (initially) dominated by processes of imitation, a larger social network causes a fewer products to lock-in. This network effect may partly explain why markets of products who are being used in a larger network, such as software or car-fuel, end up with a very few products dominating the market.

When consumers are less quickly satisfied, they will engage more in reasoned processing (deliberation or social comparison), and hence they will more quickly change their consumption. This yields a less stable market, however, in the comparer condition we see fashions occurring, which can be conceived as a temporal lock-in. Hence, in fashion markets the number 
of products will not be as large as in a market of pure deliberators. In these markets it appears to be less difficult to introduce a new product. Within a fashion market it appears to be optimal to introduce a new product when the 'old' product is very popular. Whereas in the 'growth' phase of the popular product the frequent social processing propels a further growth, when the 'top' has reached, more consumers are likely to deliberate about alternative products. When a critical mass of consumers appears to like the newly introduced product, there is a high chance that this product will also becomes fashion. However, the fashion will be temporary, and the product will ultimately disappear from the market. This is not the case in the deliberator condition, where a product may remain on the market for a prolonged period of time, as long as it is for a certain number of consumers the most attractive product. The more a new product satisfies the needs of consumers better than existing products, the larger its market share will become. For existing products the strategy of innovation may be very tactical to respond to changes in the market, and to maximise the market share.

The simulation results suggest that when preferences change according to the socialisation effect, market dynamics of both comparers and deliberators change towards a lock-in of a few products. The market of music may provide a typical example, where listening to the same style of music as your peers (e.g., dance, baroque, metal) not only satisfies the need for identity (belonging to the group), but also elicits changes in the preferences for this musical style. This socialisation effect may be more manifest when the product in question is closer related to the belief system that people have (e.g., the rebellious value of driving a Harley Davidson motorcycle). The simulation results here also indicate that a larger social network only affects the comparers, suggesting that fashion markets tend to stabilise when information is spreading more quickly.

The results of the simulation experiments illustrate the importance of psychological factors of consumers to explain variety of market dynamics. We are aware of the explorative nature of this research. Future work might explicitly study the impact of diversity among consumers and products, and the structure of social networks. We hope that this paper has shown the use of social simulation to explore possible behaviour of the system. The hypotheses that result from the model exercises can be of help for setting up new experimental studies. The combination of simulation models and experimental work is expected to generate synergetic effects which is necessary to understand complex behavioural systems. 


\section{Acknowledgements}

We thank Jasper Noordam for his contributions on a precursor of the model as presented in this paper. Furthermore, we thank the editor and two anonymous reviewers for constructive comments on an earlier version of this paper. For more information on the consumat approach we refer to http:// go.to/consumats.

\section{References}

Ajzen, I. (1991). The theory of planned behavior. Organizational Behavior and Human Decision Processes, $50,179-211$.

Albert, R., Jeong, H., \& Barabási, A.-L. (1999). Diameter of the world-wide web. Nature, 401, 130-131.

Arthur, W. B. (1994). Increasing returns and path dependence in the economy. Ann Arbor, MI: The University of Michigan Press.

Bandura, A. (1986). Social foundations of thought and action: A social cognitive theory. Englewood Cliffs, NJ: Prentice-Hall.

Becker, G. S. (1996). Accounting for tastes. Cambridge, MA: Harvard University Press.

Banerjee, A. V. (1992). A simple model of herd behavior. Quarterly Journal of Economics, 107 (3), $797-$ 817.

Bikhchandani, S., Hirshleifer, D., \& Welch, I. (1992). A theory of fads, fashion, custom and cultural change as information cascades. Journal of Political Economy, 100, 992-1026.

Bikhchandani, S., Hirshleifer, D., \& Welch, I. (1998). Learning from the behavior of others: Conformity fads and informational cascades. Journal of Economic Perspectives, 12 (3), 151-170.

Bowles, S. (1998). Endogenous preferences: The cultural consequences of markets and other economic institutions. Journal of Economic Literature, 36, 75-111.

Bowles, S., \& Gintis, H. (1976). Schooling in capitalist America: Educational reform and the contradictions of economic life. New York: Basic Books.

Brenner, T. (1999). Modelling learning in economics. Cheltenham (UK): Edward Elgar.

Chao, A., \& Schor, J. B. (1998). Empirical tests of status consumption: Evidence from women's cosmetics. Journal of Economic Psychology, 19 (1), 107-131.

Cialdini, R. B., Kallgren, C. A., \& Reno, R. R. (1991). A focus theory of normative conduct: A theoretical refinement and reevaluation of the role of norms in human behavior. In L. Berkowitz (Ed.), Advances in experimental social psychology (vol. 24) (pp. 201-234).

Clark, A., \& Oswald, A. (1994). Unhappiness and unemployment. Economic Journal, 104, 648-659.

Corneo, G., \& Jeanne, O. (1999). Segmented communication and fashionable behavior. Journal of Economic Behavior and Organization, 39, 371-385.

Cross, H. A., Halcomb, C. G., \& Matter, W. W. (1967). Imprinting or exposure learning in rats given early auditory stimulation. Psychonomic Science, 7, 233-234.

David, P. A. (1985). Clio and the economics of QWERTY. AEA Papers and Proceedings, 75 (2), $332-337$.

Duesenberry, J. S. (1949). Income, saving, and the theory of consumer behaviour. Cambridge, MA: Harvard University Press.

Elias, N. (1984). The civilizing process (translated from German). Oxford: Blackwell.

Faucheux, S., \& Moscovici, C. (1972). Social influence, conformity, bias and the study of active minorities. In L. Berkowitz (Ed.), Advances in experimental social psychology (vol. 6) (pp. 149-202).

Festinger, L. (1954). A theory of social comparison processes. Human Relations, 7, 117-140. 
Fishbein, M., \& Ajzen, I. (1975). Belief, attitude, intention and behaviour: An introduction to theory and research. Reading, MA: Addison-Wesley.

Foxall, G. R. (1990). Consumer psychology in behavioural perspective. London: Routledge.

Gintis, H. (1972). A radical analysis of welfare economics and individual development. The Quarterly Journal of Economics, 86 (4), 572-599.

Granovetter, M., \& Soong, R. (1986). Threshold models of interpersonal effects in consumer demand. Journal of Economic Behaviour and Organization, 7, 83-99.

Güth, W., \& Yaari, M. E. (1992). Explaining reciprocal behaviour in simple strategic games: An evolutionary approach. In U. Witt (Ed.), Explaining process and change. Ann Arbor, MI: University of Michigan Press.

Hayakawa, H. (2000). Bounded rationality, social and cultural norms, and interdependence via reference groups. Journal of Economic Behavior and Organization, 43, 1-34.

Hayakawa, H., \& Venieris, Y. P. (1977). Consumer interdependence via reference groups. Journal of Political Economy, 85, 599-615.

Jager, W. (2000). Modelling consumer behaviour. Ph.D. thesis, University of Groningen.

Janis, I. L., \& Mann, L. (1977). Decision making: A psychological study of conflict, choice and commitment. New York/London: The Free Press.

Janssen, M. A., \& Jager, W. (1999). An integrated approach to simulating behavioural processes. A case study of the lock-in of consumption patterns. Journal of Artificial Societies and Social Simulation, 2 (2). Available: www.soc.surrey.ac.uk/JASSS/2/2/2.html.

Kirman, A. (1993). Ants, rationality and recruitment. Quarterly Journal of Economics, 108 (1), 137-156.

Latané, B. (1981). Psychology of social impact. American Psychologist, 36, 343-356.

Maslow, A. H. (1954). Motivation and personality. New York: Harper and Row.

Max-Neef, M. (1992). Development and human needs. In P. Ekins, \& M. Max-Neef (Eds.), Real-life economics: Understanding wealth creations. London, New York: Routledge.

McCauley, C., Rozin, P., Schwartz, B. (1994). On the origin and nature of preferences and values. Unpublished paper, October 1994.

Milgrams, S. (1967). The small world problem. Psychology Today, 2, 60-67.

Neumark, D., Postlewaite, A. (1995). Relative income concerns and the rise in married women's employment. NBER working paper no.5044. NBER, Cambridge, MA.

Newell, A., \& Simon, H. A. (1972). Human problem solving. Englewood Cliffs, New Jersey: Prentice-Hall.

Newman, M. E. J., (1999). Small worlds - the structure of social networks. Santa Fe Institute working paper, 99-12-080, Santa Fe, NM.

Pavlov, I. P. (1927). Conditioned reflexes. New York: Oxford University Press.

Pollak, R. A. (1978). Endogenous tastes in demand and welfare analysis. American Economic Review, 68 (2), 374-379.

Skinner, B. F. (1953). The behavior of organisms. New York: Appleton-Century-Crofts.

Shiffrin, R. M. (1975). Capacity limitations in information processing, attention and memory. In W. K. Estes (Ed.), Handbook of learning and cognitive processes, 4, Hillsdale, NJ: Erlbaum.

Stevenson, R. J., \& Yeomans, M. R. (1995). Does exposure enhance liking for the chilli burn? Appetite, 24 (2), 107-120.

Vallacher, R. R., \& Nowak, A. (1994). The chaos in social psychology. In R. R. Vallacher, \& A. Nowak (Eds.), Dynamical systems in social psychology. San Diego: Academic Press.

Veblen, T. (1899). The theory of the leisure class. New York: Macmillan.

Watts, D. J., \& Strogatz, S. H. (1998). Collective dynamics of "small-world" networks. Nature, 393, 440442 .

Witt, U. (1991). Economics sociobiology and behavioural psychology on preferences. Journal of Economic Psychology, 12, 557-573.

Witt, U. (1997). "Lock-in" vs. "critical masses" - industrial change under network externalities. International Journal of Industrial Organization, 15, 753-773. 
Zajonc, R. B. (1968). The attitudinal effects of mere exposure. Journal of Personality and Social Psychology, 9 (2), 1-27.

Zellner, D. A. (1991). How foods get to be liked: Some general mechanisms and some special cases. In R. C. Bolles (Ed.), The hedonics of taste. Hillsdale, NJ: Lawrence Erlbaum. 